\title{
Multicomponent quantification of Astragalus residue fermentation liquor using ion chromatography-integrated pulsed amperometric detection
}

\author{
YING ZHANG $^{1}$, JIARONG WU ${ }^{1}$, QUANHUI NI ${ }^{1}$ and HONG DONG ${ }^{2}$ \\ ${ }^{1}$ School of Chinese Herbal Medicine, Guangzhou University of Chinese Medicine, Guangzhou, \\ Guangdong 510006; ${ }^{2}$ Beijing Key Laboratory of Traditional Chinese Veterinary Medicine, \\ Beijing University of Agriculture, Beijing 102206, P.R. China
}

Received July 22, 2016; Accepted March 6, 2017

DOI: 10.3892/etm.2017.4673

\begin{abstract}
Chinese medicine residues contain abundant cellulose and hemicellulose, which are potential renewable carbon sources for ethanol production. The aim of the present study was to develop a rapid and reliable method to evaluate the cellulose and hemicellulose utilization in Chinese medicine residues. In the present study, key hydrolysates (arabinose, galactose, glucose, xylose, and cellobiose) of the cellulose and hemicellulose in fermentation liquor of Astragalus residues were simultaneously quantified by ion chromatography using an integrated pulsed amperometric detector (IPAD). HPLC analysis was performed on a Dionex ICS-2500 equipped with GP50 gradient pump and ED50 IPAD. The working and reference electrodes were gold electrode and $\mathrm{Ag} / \mathrm{AgCl}$ electrode, respectively. Separation was achieved on serial no. 002627 Dionex Analytical column $(2 \times 250 \mathrm{~mm})$. Sodium hydroxide of $250 \mathrm{mM}$ and water were used as the mobile phase with a flow rate of $0.2 \mathrm{ml} / \mathrm{min}$. The temperature of column was kept at $30^{\circ} \mathrm{C}$. This method was validated for accuracy and precision. The regression equation revealed a good linear relationship $\left(\mathrm{R}^{2}=0.9959-0.9984\right)$ within the test ranges. The limits of detection and quantification for five standard analytes (arabinose, galactose, glucose, xylose and cellobiose) were in the range of 0.067-0.091 and 0.08-0.23 mg/l, respectively. The method showed good reproducibility for the quantification of five analytes in fermentation liquor of Astragalus residue with intra-and inter-day variations less than $3.843 \%$.
\end{abstract}

Correspondence to: Dr Ying Zhang, School of Chinese Herbal Medicine, Guangzhou University of Chinese Medicine, 232 Waihuan Road, Guangzhou, Guangdong 510006, P.R. China

E-mail: tjxyzyzy@hotmail.com

Dr Hong Dong, Beijing Key Laboratory of Traditional Chinese Veterinary Medicine, Beijing University of Agriculture, Beijing 102206, P.R. China

E-mail: donghong523@163.com

Key words: multicomponent quantification, Astragalus residue, ion chromatography-integrated pulsed amperometric detection

\section{Introduction}

Cellulosic ethanol generated from lignocellulosic biomass such as agricultural residues has been recognized as one of the most sustainable biofuels for transportation $(1,2)$. Chinese medicine residues, which have been treated at high temperature, contain cellulose, hemicellulose, lignin, fat, protein, and polysaccharide $(3,4)$. It is a very promising biomass material for its soft texture and large production.

Cellulose and hemicelluloses are the substrates for ethanol production (5-8). In fact, cellulose and hemicelluloses are first hydrolyzed to yield arabinose, galactose, glucose, xylose, and cellobiose. Then, glucose and xylose are fermented to produce ethanol. The traditional strain used to produce ethanol is Saccharomyces cerevisiae (S. cerevisiae). Due to $S$. cerevisiae not having a specialized xylose transport system, it utilizes xylose only after glucose is depleted in the fermentation broth and then xylose is transferred by the hexose transport system $(9,10)$. For the sake of simultaneously converting glucose and xylose to ethanol, we used a fusant, obtained by protoplast fusion, combining Pichia stipitis with S. cerevisiae. Thus, in the process of simultaneous saccharification and co-fermentation (SSCF), a variety of sugars and monosaccharides can be produced. With the purpose of valuation of cellulose and hemicellulose utilization, it is necessary to develop an accurate analysis method for the simultaneous determination of these compounds.

Several detectors coupled with chromatographic systems have been used to quantify sugars. Common detection methods include mass spectrometry (MS) $(11,12)$, refractive index detection (RID) $(13,14)$, evaporative light scattering detection (ELSD) (15-17), charged aerosol detection (CAD) $(18,19)$, and integrated pulsed amperometric detector (IPAD) (20). Ligand-exchange and cation-exchange chromatography with RID (21), and high-performance anion-exchange chromatography with IPAD (HPAEC-IPAD) $(20,22)$ have been successfully applied to monitor carbohydrates.

HPAEC-IPAD enables the rapid monitoring of monomeric and dimeric sugars in the aqueous extracts and hydrolysates of biomass. The pKa of carbohydrates ranges from 12 to 14 (23). Carbohydrates exist in the forms of negative ion in strong 
alkaline neurogen. Therefore, they can be separated by the IEC (24). Since carbohydrate is separated in strong alkaline neurogen, its detection methods should be applicable to the alkaline conditions. IPAD is technologically suitable. More importantly, derivatization reaction and sample purification are not needed. Moreover, IPAD can precisely detect the quantity of carbohydrate from pmol to fmol. Pulsed amperometric detection is suitable for trace component analysis and it is a universal and non-specific method with high sensitivity (24-26). The method can provide a stable baseline even with steep gradients. Pulse amperometric detection with the larger response signal is suitable for the quantification of sugars.

In our study, the strain was a fusant. SSCF was used. Chinese medicine residue was used as the liquid fermentation substrate. Products and intermediate products are more complex because the technological line is long, the strain is unique and the substrate composition is complicated. We tried to use ELSD, RID to determine monosaccharides and disaccharides but the results were not ideal. Finally, a simple, rapid, and reliable IEC method combined with IPAD was developed for the simultaneous determination of arabinose, galactose, glucose, xylose, and cellobiose. The method facilitated the rapid analysis of sugars and degradation products in biomass degradation products.

\section{Materials and methods}

Materials and reagents. Sodium hydroxide stock solution (50\%) was purchased from Merck \& Co., Inc. (Whitehouse Station, NJ, USA) (B0921993 334 UM824). Ultrapure water prepared with Milli-Q was used in the experiment. Astragalus residues were collected from Chinese medicine factory. Xylanase and cellulase were purchased from Xiangbo Biological Technology Co., Ltd. (Guangzhou, China). HPLC-grade arabinose, galactose, glucose, xylose, and cellobiose (purity >99\%) were purchased from Sigma-Aldrich (Shanghai, China). The test strain was a fusant prepared by protoplast fusion, combining S. cerevisiae with Pichia stipitis.

Preparation of standard solution. Stock solutions of arabinose $(2.5 \mathrm{mg} / \mathrm{l})$, galactose $(2.5 \mathrm{mg} / \mathrm{l})$, glucose $(7.5 \mathrm{mg} / \mathrm{l})$, xylose $(2.5 \mathrm{mg} / \mathrm{l})$, and cellobiose $(2.0 \mathrm{mg} / \mathrm{l})$ were prepared in ultrapure water. The working standard solutions were prepared as required by appropriate dilution of stock solutions with ultrapure water. Standard solutions sugar (arabinose, galactose, and xylose) were prepared daily according to various concentrations $(0.1,0.25,0.5,1.0$ and $1.5 \mathrm{mg} / \mathrm{l})$, and standard glucose solutions of different concentrations $(0.3,0.75,1.5$, 3.0 and $4.5 \mathrm{mg} / \mathrm{l})$ were prepared. The concentrations of standard cellobiose solutions were, respectively, 0.08, 0.75, 1.5, 3 and $4.5 \mathrm{mg} / \mathrm{l}$.

Sample preparation. Astragalus residue was first pretreated with $1 \%$ sulphuric acid for $2 \mathrm{~h}$ at $120^{\circ} \mathrm{C}$. Then $0.3 \%$ yeast extracts, $0.25 \mathrm{~g} / 1\left(\mathrm{NH}_{4}\right)_{2} \mathrm{HPO}_{4}$, and $0.025 \mathrm{~g} / 1 \mathrm{MgSO}_{4} \cdot 7 \mathrm{H}_{2} \mathrm{O}$ was added into the fermentation medium and $\mathrm{pH}$ was adjusted to 4.8 with sodium hydroxide solution. Two-step SSCF technology was employed $(27,28)$. Xylanase was added to perform $8 \mathrm{~h}$ prehydrolysis. Strain and a small percentage of cellulose
Table I. HPLC gradient elution program.

Time (min)

$250 \mathrm{mM} \mathrm{NaOH}(\%)$

\begin{tabular}{rr}
\hline $0-15$ & 4 \\
$15-20$ & $4-30$ \\
$20-35$ & 30 \\
\hline
\end{tabular}
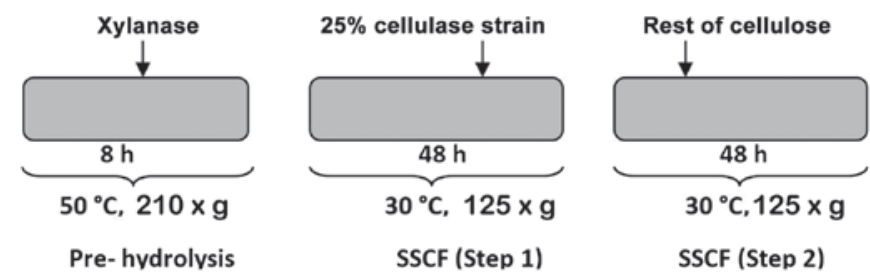

Figure 1. Schematic diagram of two-step simultaneous saccharification and co-fermentation (SSCF).

were then added into the hydrolyzate to carry out SSCF (step one) for $48 \mathrm{~h}$. After $48 \mathrm{~h}$, the remaining cellulose was fed to release glucose from glucan and subsequently fermented to generate ethanol with the fusant (Fig. 1).

The fermentation liquor was centrifuged at $10,000 \mathrm{x} \mathrm{g}$ for $10 \mathrm{~min}$. Then the supernatant was diluted 5,000-fold and filtered through $0.45 \mu \mathrm{m}$ Millipore filter. The filtrate was collected as the sample solution.

HPAEC-IPAD instrumentation and chromatographic conditions. HPLC analysis was performed on a Dionex ICS-2500 equipped with GP50 gradient pump and ED50 IPAD. Working and reference electrodes were, respectively, gold and silver electrodes. Separation was achieved on serial no. 002627 Dionex Analytical column (2x250 mm) (Dionex, Sunnyvale, CA, USA). The mobile phase consisted of $250 \mathrm{mM}$ sodium hydroxide and water. The elution program is shown in Table I. Each elution run was completed within $35 \mathrm{~min}$. The rate of the flow was $0.2 \mathrm{ml} / \mathrm{min}$ and an aliquot of $25 \mu \mathrm{l}$ of sample solution was injected into the HPAEC-IPAD system. The column temperature was set to $30^{\circ} \mathrm{C}$ for separation and determination.

Calibration curves and limits of detection and quantification. First, $25 \mu \mathrm{l}$ of each solution was injected in duplicates to construct calibration curves. The limits of detection (LOD) and quantification (LOQ) were determined at signal-to-noise ratios $(\mathrm{S} / \mathrm{N})$ of 3 and 10 , respectively. The LOD and LOQ values were experimentally verified by injecting standard solutions of the compounds at the LOD and LOQ concentrations.

Accuracy. The recovery test was used to evaluate the detection accuracy. In the recovery experiments, the selected samples were also spiked with known amounts of arabinose, galactose, glucose, xylose, and cellobiose $(0.1 \mathrm{mg} / \mathrm{l})$, and then analyzed according to the chromatographic conditions described above. The average recoveries were calculated as: Recovery $(\%)=($ the observed amount - original amount $) /$ the spiked amount x $100 \%$. 
Table II. Regression equation and LOD and LOQ for arabinose, galactose, glucose, xylose, and cellobiose.

\begin{tabular}{lcccccc}
\hline Compounds & $\begin{array}{c}\text { Retention } \\
\text { time (min) }\end{array}$ & $\begin{array}{c}\text { Regression } \\
\text { equation }\end{array}$ & $\begin{array}{c}\text { Linearity } \\
\text { range }(\mathrm{mg} / \mathrm{l})\end{array}$ & $\mathrm{R}^{2}$ & $\begin{array}{c}\text { LOD }(\mathrm{mg} / \mathrm{l}), \\
\mathrm{S} / \mathrm{N}=3\end{array}$ & $\begin{array}{c}\text { LOQ }(\mathrm{mg} / \mathrm{l}), \\
\mathrm{S} / \mathrm{N}=10\end{array}$ \\
\hline Arabinose & 7.269 & $\mathrm{Y}=10.998 \mathrm{X}-0.0866$ & $0.10-1.50$ & 0.9959 & 0.067 & 0.10 \\
Galactose & 9.085 & $\mathrm{Y}=10.701 \mathrm{X}-0.0297$ & $0.10-1.50$ & 0.9984 & 0.082 & 0.10 \\
Glucose & 9.852 & $\mathrm{Y}=12.929 \mathrm{X}-0.2877$ & $0.30-4.50$ & 0.9979 & 0.074 & 0.23 \\
Xylose & 11.009 & $\mathrm{Y}=10.669 \mathrm{X}-0.0978$ & $0.10-1.50$ & 0.9977 & 0.091 & 0.10 \\
Cellobiose & 29.469 & $\mathrm{Y}=7.3485 \mathrm{X}-0.0588$ & $0.08-1.20$ & 0.9971 & 0.080 & 0.08 \\
\hline
\end{tabular}

LOD, limits of detection; LOQ, limits of quanitification; $\mathrm{S} / \mathrm{N}$, signal-to-noise ratio.
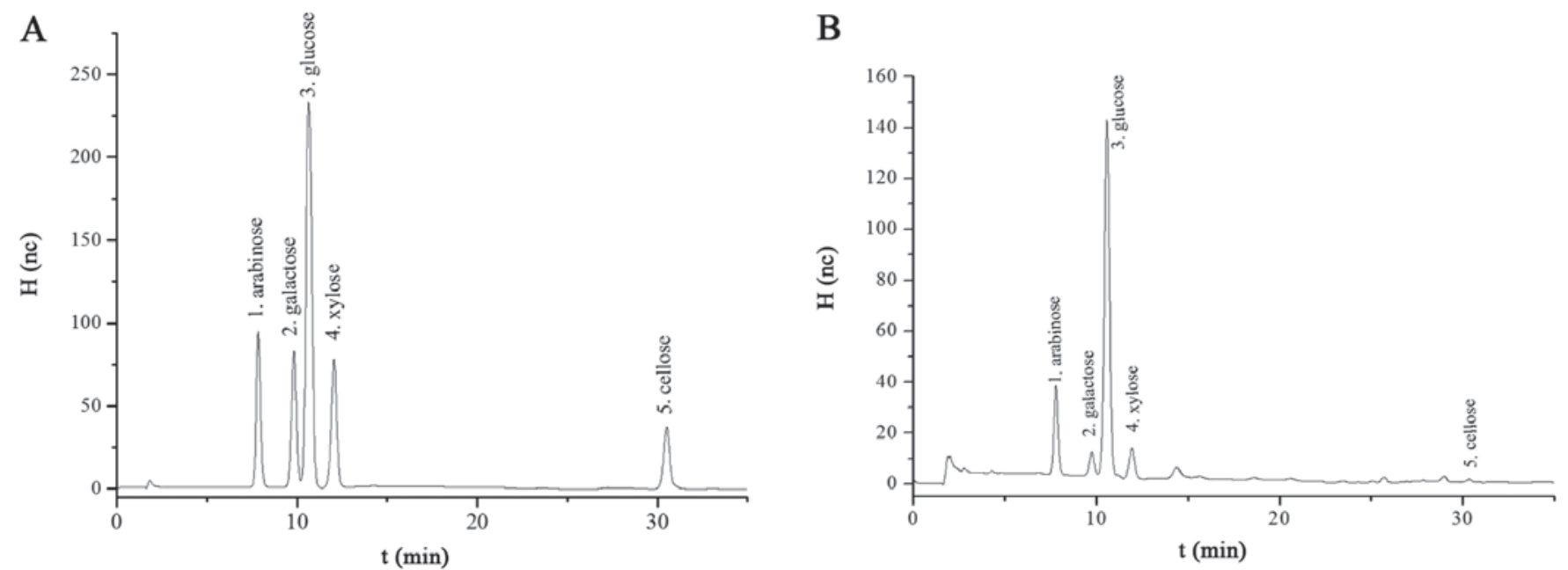

Figure 2. IEC-PAD chromatogram of arabinose, galactose, glucose, xylose, and cellobiose. (A) Standard solution and (B) sample. Calibration curves were plotted with LC Chameleon software. The regression equations, $\mathrm{R}^{2}$, RSD, retention time, limits of detection (LOD) and quantification (LOQ) of the five compounds are listed in Table II. All calibration curves showed good linear regressions in the range $\left(\mathrm{R}^{2}=0.9959-0.9984\right)$. The LODs $(\mathrm{S} / \mathrm{N}=3)$ and LOQs $(\mathrm{S} /$ $\mathrm{N}=10$ ) for sugars were within the ranges of $0.067-0.091$ and $0.19-0.25 \mathrm{mg} / 1$, respectively).

Precision. In 3 consecutive days, the intra- and inter-day precisions were determined through five injections of the sample solution. Additionally, the reproducibility and repeatability of the advanced method were determined by measuring the retention time and peak areas.

\section{Results and Discussion}

The chromatogram by HPAEC-IPAD for the standard compounds and sample is shown in Fig. 2, and Table II. The results demonstrated that the five compounds were well separated by the serial no. 002627 Dionex analytical column. From this point of view, the quantitative determinations of arabinose, galactose, glucose, xylose, and cellobiose in the fermentation liquor of Astragalus residue were feasible.

Table III gives the recovery and precision data for five compounds. Recovery experiments were performed to determine the detection accuracy of the method. The samples were analyzed before and after the addition of known amounts of arabinose, galactose, glucose, xylose, and cellobiose. The recoveries ranged from 97.83 to $102.05 \%$. The intra- and inter-day $\% \mathrm{RSD}$ of retention time and peak areas have low values $(<3.843 \%)$. Therefore, the developed IEC-PAD showed a high precision, accuracy, and sensitivity for the simultaneous quantitative evaluation of arabinose, galactose, glucose, xylose, and cellobiose in fermentation liquor of Astragalus residues.

The HPAEC-IPAD method was applied to analyze arabinose, galactose, glucose, xylose, and cellobiose (Table IV). Glucose concentration $(17.57 \mathrm{~g} / \mathrm{l})$ in fermentation liquor was the highest, indicating that glucose utilization rate was not high. It was then necessary to study the way to improve the utilization of glucose. The following step was based on the process optimization to improve the utilization of glucose and increase the ethanol yield.

The ion chromatography (IC) pulse ampere detection method has a high detection sensitivity to sugar and reaches the level in $\mu \mathrm{g} / 1$. The method is suitable for the detection of compounds with a low concentration. If the sample concentration was higher, REDOX reaction may not have been fully completed; thus leading to a lower measurement value than the actual value. As a result, it is necessary to dilute the sample to the suitable concentration. In our experiments, the supernatant was diluted 5,000-fold and the concentration was in the range of the standard curve.

When the mobile phase was $250 \mathrm{~mm} \mathrm{NaOH}:$ Water $=4: 96 \%$, monosaccharide components can be completely removed. 
Table III. Precision data of retention time and peak areas.

\begin{tabular}{|c|c|c|c|c|c|c|c|c|c|c|c|c|c|}
\hline \multirow[b]{3}{*}{ Compounds } & \multicolumn{9}{|c|}{ Intra-day precision $(\mathrm{n}=3$, mean $), \% \mathrm{RSD}$} & \multirow{2}{*}{\multicolumn{3}{|c|}{$\begin{array}{l}\text { Inter-day precision } \\
(\mathrm{n}=9, \text { mean }), \% \text { RSD }\end{array}$}} & \multirow[b]{3}{*}{ Recovery (\%) } \\
\hline & \multicolumn{3}{|c|}{ Day 1} & \multicolumn{3}{|c|}{ Day 2} & \multicolumn{3}{|c|}{ Day 3} & & & & \\
\hline & $\mathrm{t}_{\mathrm{R}}^{\mathrm{a}}$ & $\mathrm{P}_{\mathrm{A}}^{\mathrm{b}}$ & $\mathrm{H}_{\mathrm{C}}^{\mathrm{c}}$ & $t_{R}$ & $\mathrm{P}_{\mathrm{A}}$ & $\mathrm{H}_{\mathrm{C}}$ & $\mathrm{t}_{\mathrm{R}}$ & $\mathrm{P}_{\mathrm{A}}$ & $\mathrm{H}_{\mathrm{C}}$ & $t_{R}$ & $\mathrm{P}_{\mathrm{A}}$ & $\mathrm{H}_{\mathrm{C}}$ & \\
\hline Arabinose & 0.780 & 0.967 & 2.386 & 1.697 & 2.135 & 3.242 & 0.865 & 0.122 & 1.975 & 1.895 & 1.427 & 3.090 & 97.83 \\
\hline Galactose & 0.886 & 0.555 & 1.492 & 1.505 & 2.961 & 2.712 & 0.809 & 0.633 & 2.258 & 2.043 & 2.351 & 2.713 & 99.06 \\
\hline Glucose & 0.801 & 0.301 & 0.270 & 1.424 & 0.373 & 0.982 & 0.877 & 0.699 & 1.082 & 1.906 & 0.643 & 1.766 & 98.47 \\
\hline Xylose & 0.785 & 1.105 & 1.229 & 1.718 & 0.691 & 0.671 & 0.840 & 1.609 & 0.483 & 1.359 & 1.265 & 1.401 & 99.49 \\
\hline Cellobiose & 0.362 & 0.806 & 1.215 & 0.383 & 2.600 & 2.313 & 0.165 & 2.630 & 3.233 & 0.895 & 2.639 & 3.843 & 102.05 \\
\hline
\end{tabular}

${ }^{\mathrm{a}} \% \mathrm{RSD}$ of retention time; ${ }^{\mathrm{b}} \% \mathrm{RSD}$ of peak area; ${ }^{\mathrm{c}} \% \mathrm{RSD}$ of hydrolysate concentration.

Table IV. Results of HPAEC-IPAD.

\begin{tabular}{lccccc}
\hline Compounds & Arabinose & Galactose & Glucose & Xylose & Cellobiose \\
\hline Concentrations $(\mathrm{g} / \mathrm{l})$ & 4.19 & 1.33 & 17.57 & 0.81 & 0.035 \\
\hline
\end{tabular}

However, cellobiose was retained in the chromatographic column. To strengthen the elution effect, the gradient elution program was used. After increasing the proportion of $\mathrm{NaOH}$ to $20 \%$, cellobiose which has strong adsorption ability can be eluted. The final eluent condition was provided as follows: 0-15 $\mathrm{min}, 250 \mathrm{~mm} \mathrm{NaOH}$ with $4 \%$; $15-20 \mathrm{~min}$, from $4 \%$ to 30\%; 20-35 min, maintaining 30\%.

The content determination method was suitable for Astragalus residues fermentation medium, as well as for other fermentation liquids of Chinese medicinal drugs. We have applied the method to other media, such as Kudzu, Patchouli and it showed good adaptability. The developed experimental means is very useful for evaluating resource utilization of traditional Chinese medicine.

In conclusion, the analysis was carried out on a Dionex Analytical column (2x250 mm). Water and $250 \mathrm{mM}$ sodium hydroxide were used as the mobile phase. The rate of the flow was $0.2 \mathrm{ml} / \mathrm{min}$. The column temperature was kept at $30^{\circ} \mathrm{C}$. The accuracy and precision of the detection method were validated. The obtained regression equation revealed a good linear relationship $\left(\mathrm{R}^{2}=0.9959-0.9984\right)$ within the test ranges. The LOD and LOQ for five analytes (arabinose, galactose, glucose, xylose, and cellobiose) were in the range of 0.067-0.091 and 0.08-0.23 mg/l, respectively. The detection method showed good reproducibility for the quantification of five analytes in fermentation liquor of Astragalus residues and the intra- and inter-day variations were $<3.843 \%$.

\section{Acknowledgements}

The present study was supported by the National Nature Science Foundation of China (81403193), the Youth Elite Project of GUCM (QNYC20140112), and the Natural Science Foundation of Guangdong Province in China (2014A030313587). The authors gratefully acknowledge Ms. Hu Yang for experiment assistance.

\section{References}

1. Balan V, Bals B, Chundawat SPS, Marshall D and Dale BE: Lignocellulosic biomass pretreatment using AFEX. Methods Mol Biol 581: 61-77, 2009.

2. Brethauer S and Wyman CE: Review: continuous hydrolysis and fermentation for cellulosic ethanol production. Bioresour Technol 101: 4862-4874, 2010.

3. Meng X, Yu H, Wang P and Rong X: Study on pyrolysis and resource utilization of herb residue for Chinese medicine industry in the perspective of low-carbon economy. Environment Pollution Control 32: 32-35, 2010 (In Chinese).

4. Wang H, Xu G, Gao W, Li D, Yu L and Sun YJ: Effects of herbal residues organic substrates on growth,yield, and quality of capsicum. Jiangsu J Agricultural Sci 25: 1301-1304, 2009 (In Chinese).

5. Shafiei M, Karimi K and Taherzadeh MJ: Pretreatment of spruce and oak by N-methylmorpholine-N-oxide (NMMO) for efficient conversion of their cellulose to ethanol. Bioresour Technol 101: 4914-4918, 2010.

6. Jeihanipour A, Karimi K, Niklasson C and Taherzadeh MJ: A novel process for ethanol or biogas production from cellulose in blended-fibers waste textiles. Waste Manag 30: 2504-2509, 2010.

7. Park I, Kim I, Kang K, Sohn H, Rhee I, Jin I and Jang H: Cellulose ethanol production from waste newsprint by simultaneous saccharification and fermentation using Saccharomyces cerevisiae KNU5377. Process Biochem 45: 487-492, 2010.

8. Jin M, Gunawan C, Balan V, Lau MW and Dale BE: Simultaneous saccharification and co-fermentation (SSCF) of AFEX(TM) pretreated corn stover for ethanol production using commercial enzymes and Saccharomyces cerevisiae 424A(LNH-ST). Bioresour Technol 110: 587-594, 2012.

9. Bertilsson M, Andersson J and Lidén G: Modeling simultaneous glucose and xylose uptake in Saccharomyces cerevisiae from kinetics and gene expression of sugar transporters. Bioprocess Biosyst Eng 31: 369-377, 2008.

10. Diderich JA, Schepper M, van Hoek P, Luttik MAH, van Dijken JP, Pronk JT, Klaassen P, Boelens HFM, de Mattos MJ, van Dam K, et al: Glucose uptake kinetics and transcription of HXT genes in chemostat cultures of Saccharomyces cerevisiae. J Biol Chem 274: 15350-15359, 1999. 
11. Puzo G and Promé JC: Mass spectrometry of acylated sugars as trimethylsilyl ether derivatives. A way for location of long chain fatty acyl groups. Biomed Mass Spectrom 5: 146-152, 1978.

12. Taylor VF, March RE, Longerich HP and Stadey CJ: A mass spectrometric study of glucose, sucrose, and fructose using an inductively coupled plasma and electrospray ionization. Int J Mass Spectrom 243: 71-84, 2005.

13. Calull M, Marcé RM and Borrull F: Determination of carboxylic acids, sugars, glycerol and ethanol in wine and grape must by ion-exchange high-performance liquid chromatography with refractive index detection. J Chromatogr A 590: 215-222, 1992.

14. Clement A, Yong D and Brechet C: Simultaneous identification of sugars by HPLC using evaporative light scattering detection (ELSD) and refractive index detection (RI). Application to plant tissues. J Liq Chromatogr Relat Technol 15: 805-817, 1992.

15. Moh M, Tang T and Tan G: Improved separation of sucrose ester isomers using gradient high performance liquid chromatography with evaporative light scattering detection. Food Chem 69: 105-110, 2000

16. Wang J, Zhou Y and Wang Q: Analysis of mycotoxin fumonisins in corn products by high-performance liquid chromatography coupled with evaporative light scattering detection. Food Chem 107: 970-976, 2008.

17. Yoo DS, Choi YH, Cha MR, Lee BH, Kim SJ, Yon GH, Hong KS, Jang YS, Lee HS, Kim YS, et al: HPLC-ELSD analysis of 18 platycosides from balloon flower roots (Platycodi Radix) sourced from various regions in Korea and geographical clustering of the cultivation areas. Food Chem 129: 645-651, 2011.

18. Moreau RA: Lipid analysis via HPLC with a charged aerosol detector. Lipid Technol 21: 191-194, 2009.

19. Beilmann B, Langguth P, Häusler H and Grass P: High-performance liquid chromatography of lactose with evaporative light scattering detection, applied to determine fine particle dose of carrier in dry powder inhalation products. J Chromatogr A 1107: 204-207, 2006.
20. $\mathrm{Yu} \mathrm{H}$ and Mou S: Methods of amperometric detection and its applications in ion chromatography. Chemistry 7: 483-488, 2007.

21. Stefansson M and Westerlund D: Ligand-exchange chromatography of carbohydrates and glycoconjugates. J Chromatogr A 720: 127-136, 1996.

22. Sevcik RS, Mowery RA, Becker C and Chambliss CK: Rapid analysis of carbohydrates in aqueous extracts and hydrolysates of biomass using a carbonate-modified anion-exchange column. J Chromatogr A 1218: 1236-1243, 2011.

23. Cai Y, Liu J, Shi Y, Liang L and Mou S: Determination of several sugars in serum by high-performance anion-exchange chromatography with pulsed amperometric detection. J Chromatogr A 1085: 98-103, 2005.

24. Jandik P, Cheng J and Avdalovic N: Analysis of amino acid-carbohydrate mixtures by anion exchange chromatography and integrated pulsed amperometric detection. J Biochem Biophys Methods 60: 191-203, 2004.

25. Thiele C, Gänzle MG and Vogel RF: Sample preparation for amino acid determination by integrated pulsed amperometric detection in foods. Anal Biochem 310: 171-178, 2002.

26. Ding Y, Yu H and Mou S: Direct determination of free amino acids and sugars in green tea by anion-exchange chromatography with integrated pulsed amperometric detection. J Chromatogr A 982: 237-244, 2002.

27. Rocklin RD and Pohl CA: Determination of carbohydrate by anion exchange chromatography with plus amperometric detection. J Liq Chromatogr 6: 1577-1590, 1983.

28. Jin M, Lau MW, Balan V and Dale BE: Two-step SSCF to convert AFEX-treated switchgrass to ethanol using commercial enzymes and Saccharomyces cerevisiae 424A(LNH-ST). Bioresour Technol 101: 8171-8178, 2010. 